This item was submitted to Loughborough's Research Repository by the author.

Items in Figshare are protected by copyright, with all rights reserved, unless otherwise indicated.

\title{
Recruitments, engagements and partitions: managing participation in play
}

\section{PLEASE CITE THE PUBLISHED VERSION}

http://dx.doi.org/10.1080/21594937.2016.1147287

\section{PUBLISHER}

(c) Taylor \& Francis

\section{VERSION}

AM (Accepted Manuscript)

\section{PUBLISHER STATEMENT}

This work is made available according to the conditions of the Creative Commons Attribution-NonCommercialNoDerivatives 4.0 International (CC BY-NC-ND 4.0) licence. Full details of this licence are available at: https://creativecommons.org/licenses/by-nc-nd/4.0/

\section{LICENCE}

CC BY-NC-ND 4.0

\section{REPOSITORY RECORD}

Butler, Carly, Rebecca Duncombe, Carolynne Mason, and Rachel Sandford. 2016. "Recruitments, Engagements and Partitions: Managing Participation in Play". Loughborough University. https://hdl.handle.net/2134/17934. 


\title{
To appear in The International Journal of Play
}

\section{Accepted April 2015}

\section{Recruitments, engagements and partitions: Managing participation in play.}

\author{
Carly W. Butler, Rebecca Duncombe, Carolynne Mason \& Rachel Sandford \\ Loughborough University
}

\begin{abstract}
This paper examines the social practices children use to manage participation in play activities. It is part of wider research looking at children's physical activity in play, and is interested in the role of social interaction in shaping active play. The focus in this article is on how children get others to take part in play they have initiated, and how the inclusion and exclusion of particular children is managed. The data examined is video-recordings of children's play with toys and boxes. Children were 7-8 years old and played in groups of four in a school setting. Drawing on a conversation analytic approach, the analysis identifies three interactional strategies used to manage the participation of other children in play: recruitments, engagements and partitions. We discuss the design and use of these strategies within the play activity. The paper contributes to studies of children's play interaction, and considers how greater understanding of social practices can contribute to understandings of children's physical activity in play. Implications of the research for interventions aimed at encouraging active play are discussed.
\end{abstract}

Key words: Active play, social interaction, primary school, conversation analysis

Word Count: 7365 (Main text and references) 
Participation in Play - Author Version - April 2015

\section{Recruitments, engagements and partitions: Managing participation in play.}

\section{Introduction}

The importance of play and the acknowledged benefits of play are endorsed by the United Nations who describe play as a fundamental right for children (Valentine \& McKendrick, 1997). In addition to the numerous social and cognitive benefits of play (e.g. Gray, 2011; Wood, 2007), there is an increasing interest in how play promotes children's physical wellbeing. Active play has been shown to have cognitive benefits (Sattelmair \& Ratey, 2009), to enhance health (Brockman et al., 2010) and to improve muscle strength, endurance and quality of movement (Feda et al., 2012). Given that play has such benefits for children's health and well-being, it is important to identify and understand factors that can facilitate or inhibit play activity. Previous research has explored a number of these factors, such as the physical environment, supervision, provision of toys and objects, and gender, but relatively little is known about the social practices of children engaged in physically active play (Ridgers et al., 2014). This paper demonstrates the value of looking at the social and interactional components of active play, through examination of the strategies children use to establish participation within play activity.

Establishing and maintaining participation in play activities is an important element in accessing the beneficial effects of play in school settings. The playground is a social space with activity often collectively organised and resources shared amongst children (Pellegrini \& Blatchford, 2000). Taking part in this collective and collaborative play can therefore be understood as a social accomplishment - something that children manage through a sophisticated array of social skills and strategies (Bateman, 2011; Butler, 2008; Corsaro, 2012). Social strategies are especially apparent in children's negotiations around who can participate in play and games, whether this is attempting to join in the play of other children, or by inviting other children to join a play activity that one has initiated. Research has identified a range of linguistic and embodied techniques that children use to try to enter into ongoing play, and to grant or prevent the access of another child to a play activity (e.g. Bateman, 2011; Cromdal, 2001; Corsaro, 1979; Goodwin, 2002; Sheldon, 1996). Particular strategies may be more successful than others. In a classic paper on play access, Corsaro (1979) noted that a straight request like 'can I play' opens up space for a rejection, whereas simply starting to engage in the same activity as the other children is more likely to result in successful play entry. Some strategies are quite complex and embedded in the play activity itself - for example, Sheldon (1996) showed how a pair of children excluded another by saying she could be the 'baby brother' but was not 'born yet'.

The focus of past research has largely been on how children enter (or fail to enter) into the play of others. We know much less about how children who want to start up a play activity attract and invite others to take part in that activity, that is, how they engage the attention and involvement of other children in initiating play. Furthermore, children also need to manage the participation of other children if a game is designed to have a limited number of 
players. Managing participation in play, then, involves dual processes of inclusion and exclusion (Bateman, 2011, 2012).

The current paper contributes to research on play interaction by exploring children's participation in play, and specifically by examining how children effectively get other children to play with them. Analysis focuses on the linguistic and embodied practices through which children initiate play activities and shape their own and others' participation in play activity through an interactional analysis that draws on conversation analytic methodology in that it is based on detailed analysis of the turn-by-turn organisation of the children's social interactions. The paper contributes to a growing body of research that has applied conversation analytic methods to study children's play - covering such topics as how play and games are organised and understood, how children's social relationships are shaped in and through play, and how specific forms of talk and interaction are used in play interaction (e.g. Bateman 2011, 2012; Bateman, Danby \& Howard, 2013; Butler \& Weatherall, 2006, 2011; Butler, 2008; Danby \& Baker, 1998; Cobb-Moore, Danby \& Farrell, 2009; Cromdal, 2001; Goodwin, 1990; Kyratzis, 2007; Theobald, 2013; Whalen, 1995). Research using this methodology has revealed the complex social and moral orders that are core to play, and demonstrated how action in play is collaboratively achieved through social interaction.

The current paper comes out of a broader study on the impact of toys on children's physical activity (Morris et al., 2012). In this research, the physical activity of children aged 7-8 was measured while playing with toys or with boxes (inside and outside), during breaktime and lunchtime, and in Physical Education classes. It was found that children spent a greater proportion of time engaged in activity of moderate-vigorous intensity during play sessions with toys and boxes (61\%), than during PE (38\%), school break (47\%) or lunch-time (36\%). While there were clearly demarcated patterns in terms of activity, the video-recordings and observational notes about the nature of play reveal individual differences in play engagement (and hence physical activity), and capture the fluidity and multi-layered relationship between play and physical activity (see Sandford et al, forthcoming). Using the video-recordings of the play and detailed transcripts, this paper explores ways in which children's talk and social interaction shapes, facilitates or impedes their engagement in play activity. Specifically it aims to examine the strategies children used to invite or encourage other children to take part in play they have initiated, and the practices through which children are included or excluded in the play activity.

\section{Data, method and analytic methodology}

Fifty one children in Year 3 (7-8 years old) from two primary schools in the Midlands of England took part in the study. The physical activity of the children was measured by an accelerometer worn around the waist of each child for the duration of the school day. The 
accelerometer recorded the intensity of the children's activity over the course of the day, and analysed this during the following times:

- Indoors with a selection of cardboard boxes to play with;

- Indoors with toys (designed to promote/enable physical activity) to play with;

- Outdoors with a selection of cardboard boxes to play with;

- Outdoors with toys (designed to promote/enable physical activity) to play with;

- School break;

- School lunch-time;

- School PE lesson.

The children were divided into groups of four for the play sessions (with toys and boxes) and remained in the same group for each of these sessions. One group from each school was mixed-sex (two girls and two boys) and the others were single-sex. The play sessions were 30 minutes long and held on four consecutive days. The outdoor sessions took place in an empty school playground and the indoor sessions in an empty room in the school (a library at one school and hall at the other). The order of the play sessions was randomised for each group, but was held at the same time each day. Toys or boxes were left in the middle of the room and children were free to play with whatever they liked during the session. Adult intervention was mostly limited to ensuring the play was safe. Children were video-recorded during the sessions, and observational notes were made. After their involvement in the play sessions, children also took part in a one-off focus group discussion (in their groups) to discuss their experiences of each condition. Repeated viewings of the recordings and transcripts of the children's talk were used to identify and analyse instances where children's participation in play was proposed, invited, accepted, denied, negotiated or otherwise managed by the children, with a focus on moments where play activities were first initiated. The analysis presented here focuses on recordings from four different play sessions. All names have been changed to protect the children's anonymity.

The data were analysed using interaction analysis, which is informed by a conversation analytic approach. Conversation analysis (CA) treats talk as action-oriented and used to do things (see Sidnell, 2010 for an introduction to CA). Transcripts include detail that has shown to be relevant for how people talk to one another - for instance, silences between or within turns at talk are timed to the micro-second, and the precise moment at which overlapping talk begins and ends is indicated with square brackets (see Appendix for transcription notations, based on Jefferson, 2004). The analytic procedure is typically data-driven, which means that the analysis is guided and shaped by what is observed in the data. Conversation analytic research examines how turns at talk are constructed, what a turn is being used to do in and for the interaction, and how the next speaker responds to the prior turn. A core feature of CA work is that analysis is grounded in what is visible in the data. The analyst does not draw on their own assumptions to explain what is happening in an interaction, but looks 
to see what evidence there is in the data of the participant's own assumptions, understandings and concerns. By using this analytic approach, we are able to look at children's play in a way that captures children's moment-by-moment production and organisation of play, and understand the interactional basis of play activity (Butler, 2008).

\section{Managing Participation in Play}

As the research design of this study involved putting four children together in a room or outside play area with a selection of toys or boxes, participation in play was implied from the outset. However, participation in specific play activities was very fluid. Within the thirty minutes of play in each session, numerous games and versions of games were proposed, each involving different numbers of children - from solitary play, to paired play, through to play involving all four children. The analysis focuses on how and when children successfully, and unsuccessfully, sought or resisted the participation of other children in their game.

The first section focuses on what we have described as recruitments - when children explicitly invite or propose the participation of another child in a play activity they are initiating. The second section considers engagements, when children seek or secure the participation of others through more implicit actions such as announcements, or embodied action. The final section looks at partitioning, illustrated by instances when children manage the inclusion or exclusion of other children.

\section{Recruitments: Requests, invitations and proposals}

Children used a range of linguistic strategies to initiate joint play. The most standard and straightforward of these strategies include requests or invitations (e.g. 'do you want to play $X$ with me?), and proposals (e.g. 'shall we play $X$ ?'). We have termed these actions recruitments as they clearly identify and seek the involvement of another child in a specific play activity, thereby actively seeking to recruit them into play. These recruitments vary in the degree to which they presuppose the engagement of the other child, as evidenced by the sorts of responses they seek from others. Put simply, some invitations or requests are closer to 'expecting' or encouraging the participation of others.

For example, the invitation format, illustrated in the following two extracts, minimises the expectation that another child will participate by explicitly seeking an acceptance or rejection.

\section{Extract 1}

S2.G4.G.In.Toys [03:07] ((Kate picks up the mitt and ball, Selena is approaching the hula hoop))

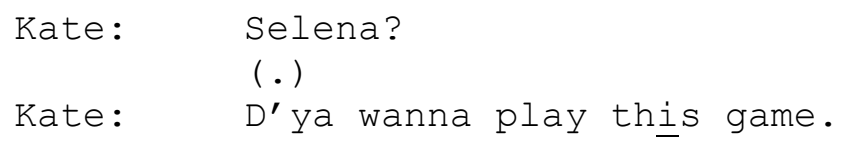




\section{Extract 2}

S2.G4.G.In.Toys [04:53] ((Kate is arranging the net on the table tennis table, Selena is behind her with the football))

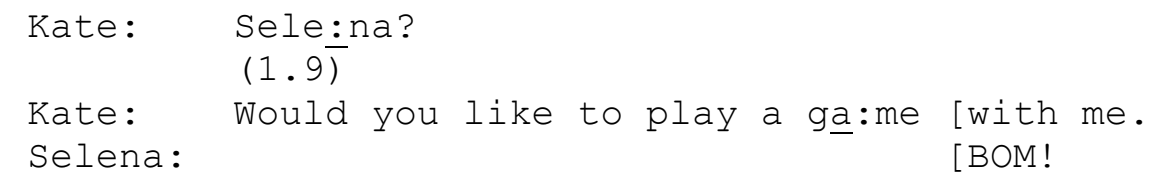

In both of these examples, Kate's invitations seek a yes or no response from Selena. In the first extract, Kate asks if Selena 'wants' to play with the Velcro mitt and ball, and in the second, whether she would 'like to play a game' of table tennis. The first thing to notice about both examples is that Kate initially addresses Selena by name - a summons (Schegloff, 2007). Because Selena's attention is elsewhere, Kate first seeks her attention as an initial step towards issuing the invitation (see Butler \& Wilkinson, 2013). By naming Selena, Kate also establishes Selena as the only child being invited which is particularly relevant in these cases as there are two other girls nearby who were available to play.

The explicit invitations involve no presuppositions that the other child will take part in the play. Use of the yes-no question makes the playing of the game entirely contingent on the addressee's response. This format also minimises the inviter's entitlement in establishing a new game activity. The relevance of this will become clearer as we look at other types of format.

The focus in extract three is on Matt's proposal at line 8. It is taken from a session with boys playing with toys indoors. Prior to the extract Tim and Jacob were playing at the football table and then left it to go and play with the bowling ball and skittles (lines 5-6). Matt and Dylan then moved from the Velcro mitt set to the now empty football table.

\section{Extract 3}

S3G5.B.In.Toys [2:22] ((Tim and Jacob playing at the football table, Dylan and Matt playing with the Velcro mitt))

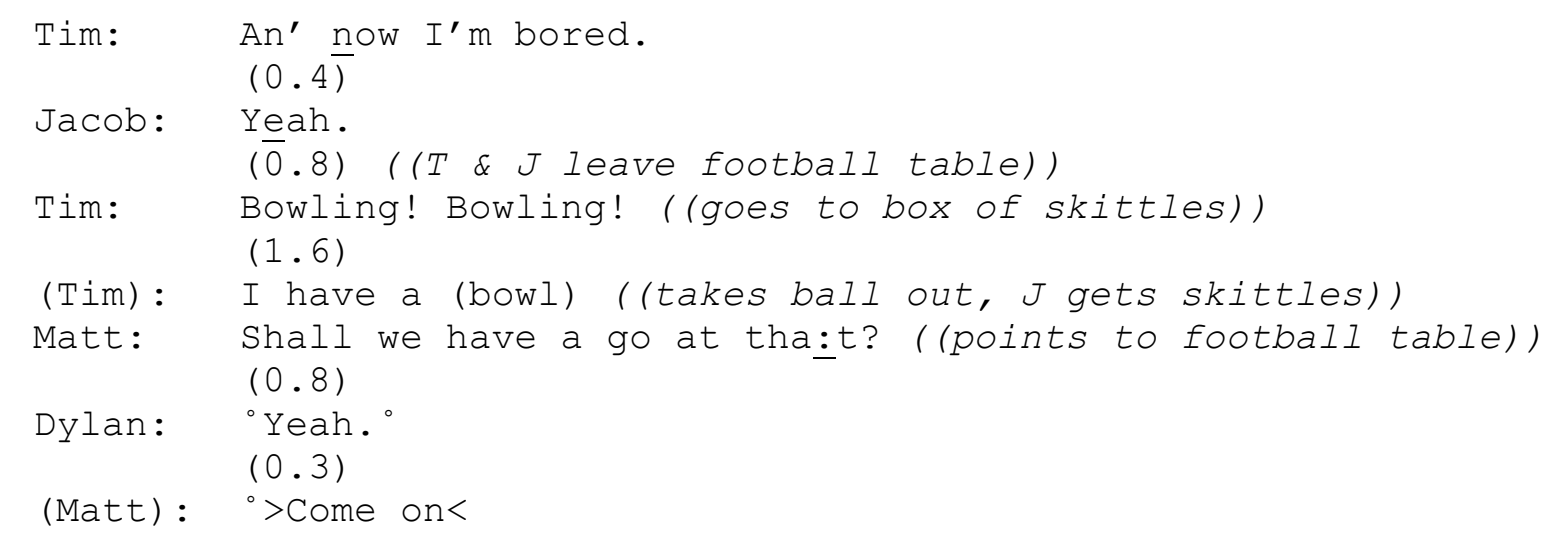


On seeing Tim and Jacob abandon the football table, Matt initiates a move from the Velcro mitt to the football table with Dylan. He points to it and asks 'shall we have a go at that' to Dylan? It is heard as more of a proposal than the invitations seen in extracts one and two. Like the invitations it does not assume joint participation in the new play activity, as it offers an opportunity for Dylan to reject the proposed activity. However the 'shall we' format embodies a stronger sense of both joint action being proposed, and a reasonable expectation that Dylan will accept this proposal. As Wootton (1997) found in looking at the development of request formats, 'shall we' formats are regularly used when the recipient has already displayed some form of commitment to the proposed action. In this case, the form of Matt's proposal may be related to the fact that he is already engaged in play with Dylan. It seems reasonable, then, to expect he may be willing to move to a new play activity with Matt.

The next extract illustrates another proposal, which this time does not involve an interrogative format:

\section{Extract 4}

S2G3.G.In.Box. [00:19]

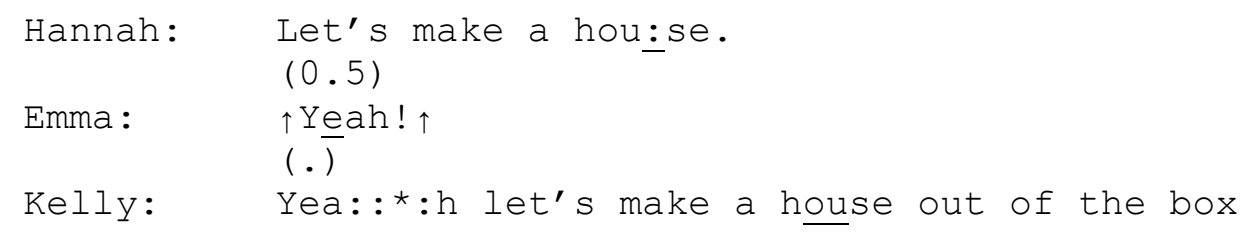

The girls had just begun an indoors play session with boxes. Hannah proposes making a house through the assertion 'let's make a house'. As we have seen, alternatives to this are to ask or invite the other children to make a house, by using a questioning (or interrogative) format. By using the form of an assertion, Hannah's turn has the potential to be treated as a directive. It embodies a presupposition of agreement from the other children, which is less the case with the other formats we have discussed. With this format, the relevant response by the other children is an agreement, rather than acceptance.

The collective term 'let's' demonstrates that what is proposed is a joint activity, that includes all other children as play participants. The proposal is readily and enthusiastically taken up with Emma's 'yeah' displaying an agreement. Kelly also agrees, and then repeats the proposal herself with the addition of the more specific, 'out of the box' (line 5). With this repeat and extension Kelly further treats the play activity as collective and also establishes herself as a 'co-proposer' of the game. This pushes back against the authority Hannah could be seen to assert with her initial proposal, and may have relevance for how the children manage ownership of play. The matter of who makes the initial proposal can have further implications for how activities within the play are managed. 
In the last example of a recruitment, Matt issues an invitation to play with a summons, gesture and plea. While there is some verbal interaction, there is no naming of the game, nor an explicit proposal or invitation. Tim and Jacob are occupied playing 'tiny table tennis' while Dylan is kicking a ball secured to a plastic mat. Matt picks up the Velcro mitt and ball then holds it out towards Dylan whose head is down:

\section{Extract 5}

S3G5.In.Toys [06:50]

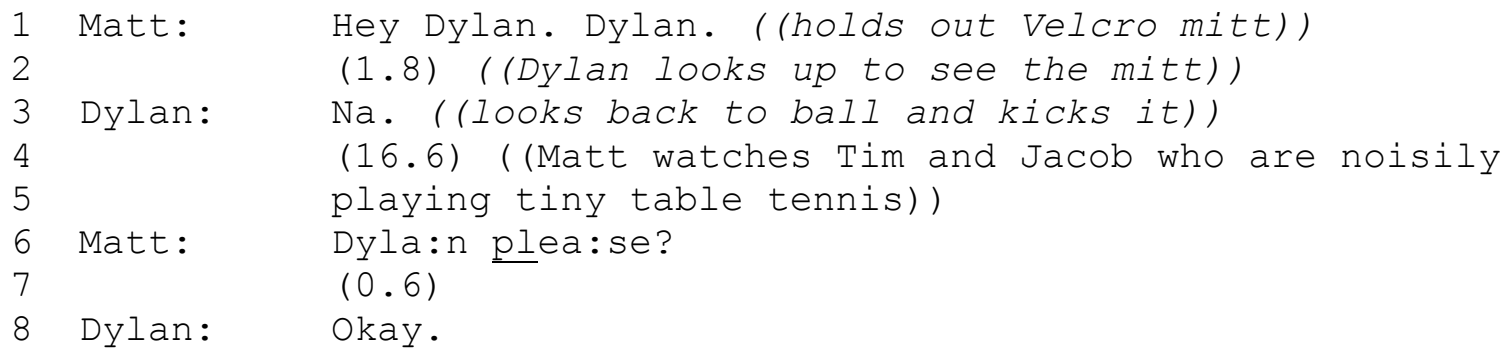

Matt's invitation for Dylan to play with him is done primarily through gesture. He issues as summons, as Kate did in extracts 1 and 2, to get Dylan's attention, and then holds out the velcro mitt. Dylan's response is minimal - a fairly quiet 'na' before he returns his attention back to the ball he is kicking. Dylan recognises Matt's actions as a play invitation but rejects it, leaving Matt without a play partner, or a play activity. Matt watches Tim and Jacob play tiny table tennis for 16 seconds, seeming to abandon his recruitment attempt. However, he then has a second go at inviting Dylan to play with him, with a pleading 'please'. This time he is successful, and the pair go on to play with the mitt and ball. So, in this example, there is an explicit recruitment, without verbalisation of the play activity. Participation of the invited child only comes about via persistence and pleading. There is a strong contrast in terms of the expectancies embodied in lines 1 and 6 . In line 1, the lack of an explicit request and the holding out of the mitt seems to assume an acceptance. However, the subsequent plea is responsive to the prior rejection and attends to this earlier failure.

Recruitments, then, involve the use of interrogative or assertive formats for issuing invitations or proposals for another child to participate in a play activity. They manage the contingency between the play and a child's response to the invitation or proposal by making acceptance or agreement the relevant next turn. The use of one format over another demonstrates the children's monitoring of others' activity and engagement. They both reflect the child's assessment of the likelihood of an agreement or acceptance, and play an active and important part in shaping the likelihood of an agreement or acceptance. We have also noted that children identify and specify who is (and is not) being recruited as a participant via the use of summonses, and collective proterms like 'us' and 'we'. Through these practices, children produce a situated social order and demonstrate their understanding, analysis, and construction of play participation. 


\section{Engagements}

A second collection of methods for managing play participation involves what we describe as engagements. In contrast to the recruitments, which make an agreement or acceptance from another child conditionally relevant (that is, they are normatively expected in the next turn (Sacks, 1995)), engagements are not designed in ways that clearly invite a response from another child. Yet, they involve actions that seem to invite the participation of another child into a play activity. To illustrate, we return to the extract shown above in extract 3. There our interest was on Matt's proposal 'shall we have a go at that', but recall that this happened after Tim and Jacob left the football table in order to play bowling:

\section{Extract 6}

S3G5.B.In.Toys [02:22] ((Tim and Jacob playing at the football table, Dylan and Matt playing with the Velcro mitt))

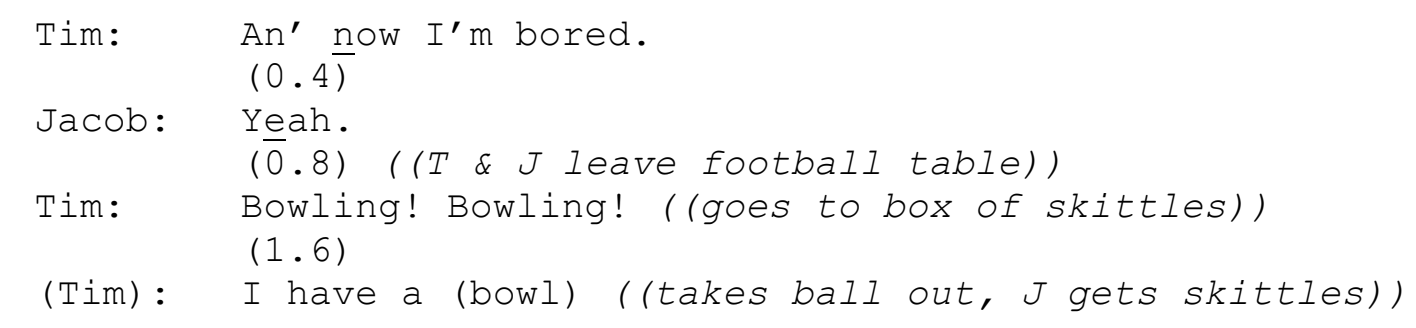

Tim initially announces boredom with the football table and turns away from it, signalling the end of his involvement with this game. He sees the cardboard box with skittles inside it and announces a possible next activity with an excited sounding 'bowling bowling!' He picks up the bowling ball which seems to indicate his role in the game, as 'bowler' (line 7) while Jacob begins to collect the skittles. Tim's announcement thus serves as both the identification of the play equipment as well a proposal for himself and Matt to begin playing with it. Their participation is secured without any explicit invitations or requests, instead it is managed through an announcement identifying a play object. Announcements, particularly animated in the way that Tim does here, are methods for seeking and establishing the engagement of another child. It is this engagement that serves to initiate their participation in the play activity.

At times, the engagement request can be more explicit. For instance, in one example Kelly had been throwing a foam boomerang, while Selena was playing with other toy objects. After one throw, Kelly laughed loudly and then said 'Selena look!' to get Selena's attention, which then led to Selena first appreciating the throw and then joining in. Thus, engagement is a step into participation.

Play initiation did not always involve explicit verbalised announcements or proposals or invitations. In addition to announcements and actions to seek attention, engagement was 
also sought by the performance of a first play action. In many cases, a child will seek the participation of others through their actions alone. With this sort of game initiation, children need to be able to produce and recognise an action as a playful one, and also need to display and understand the nature of participation that the play may involve. Conveying the meta-message 'this is play' (see Bateson, 1972) is a key aspect of inciting participation of other children in initiating a game. One example of this involved what initially looked like a case of 'stealing' another child's toy. Extract 7 offers a quite different method of game initiation - whereby Selena simply begins a game. Play activity comes about through recognition of her actions as play, and the cooperative collaboration of the other children. Given that the action is primarily non-verbal, a report of what happens is provided in place of a transcript:

\section{Extract 7}

\section{S2G4.G.In.Toy [16:20]}

Kate is bouncing on the moon hopper then falls off it, says 'I died,' and lies on the ground laughing. Kelly walks towards the moon hopper and picks it up with one handle. Selena rushes towards the hopper and falls on it with two arms wrapped around it. She picks it up, hugging it, and runs to the other side of the room with mouth open and laughing. She looks back to Kelly then falls on to the hopper lying over it protectively. Kelly runs over, laughing. Serena picks the hopper and continues to run in a circle around the room. Kate and Abbie join in the chase. Kate catches Serena and wraps her arms around her, saying 'I got ya!'. They all laugh throughout. Later in the play session, Selena repeats the 'chase' game by 'stealing' the table tennis net, and encouraging the others to chase her.

The status of this activity as play or a game is a product of the children's own actions and intersubjective understandings. When Selena takes the hopper, and later the net, she shows the other children that 'this is play' through her laughter and what Burton-Jones (1972, p. 106), working from an ethological perspective, described as a 'play face' - a smile with open mouth. An open mouth play face is a feature of rough-and-tumble play that helps display a playful rather than aggressive affect (Pellegrini \& Smith, 1998). The demonstration of a playful and positive affect serves in this case as a cue for the other children to chase Selena. In this way, an action that could be seen as disruptive to another child's play or the basis for a dispute becomes the initiation of joint, active play. Selena relies not just on her own actions to establish this new play, but on the other children's recognition of the act as playful. Here, laughter and embodied action is central to the production and recognition of play.

One way of making sense of how this aspect of game initiation occurs is via Harvey Sacks's notion of 'mapping'. Sacks (1995) proposed that games can be understood to be composed of category sets of players and activities. Games, and actions that take place within them, are organised in terms of the membership of the children within the relevant play 
categories. It was suggested by Sacks that children 'map' themselves onto player categories at systematic moments during play - for example, on initiating a game and on the arrival of a new member (see Butler \& Weatherall (2006) and Butler (2008) for further discussion, illustration and development of Sacks's work on play). In extract 7, then, Selena's displays of 'running away' maps her as a player in a game of chase, in which other children are potential members in the category of 'chasers'.

Extract 8 illustrates how mapping featured as a method for play initiation. The fragment comes just over eleven minutes into a boys play session with cardboard boxes. Prior to this point the boys had been using the boxes as 'dens', but, more generally were putting the boxes on their heads (described at one point as a helmet) and walking around. At this stage in the play, the boxes were beginning to fall apart through use as play objects. Where the extract picks up the action, Liam and Sam both use mapping in order to start a new direction to the play. However, Liam's moves do not initiate a new play theme, whereas Sam is more successful and starts a form of play that resulted in several minutes of intense physical activity by the children.

\section{Extract 8}

S1G1.In.Box [11:32]

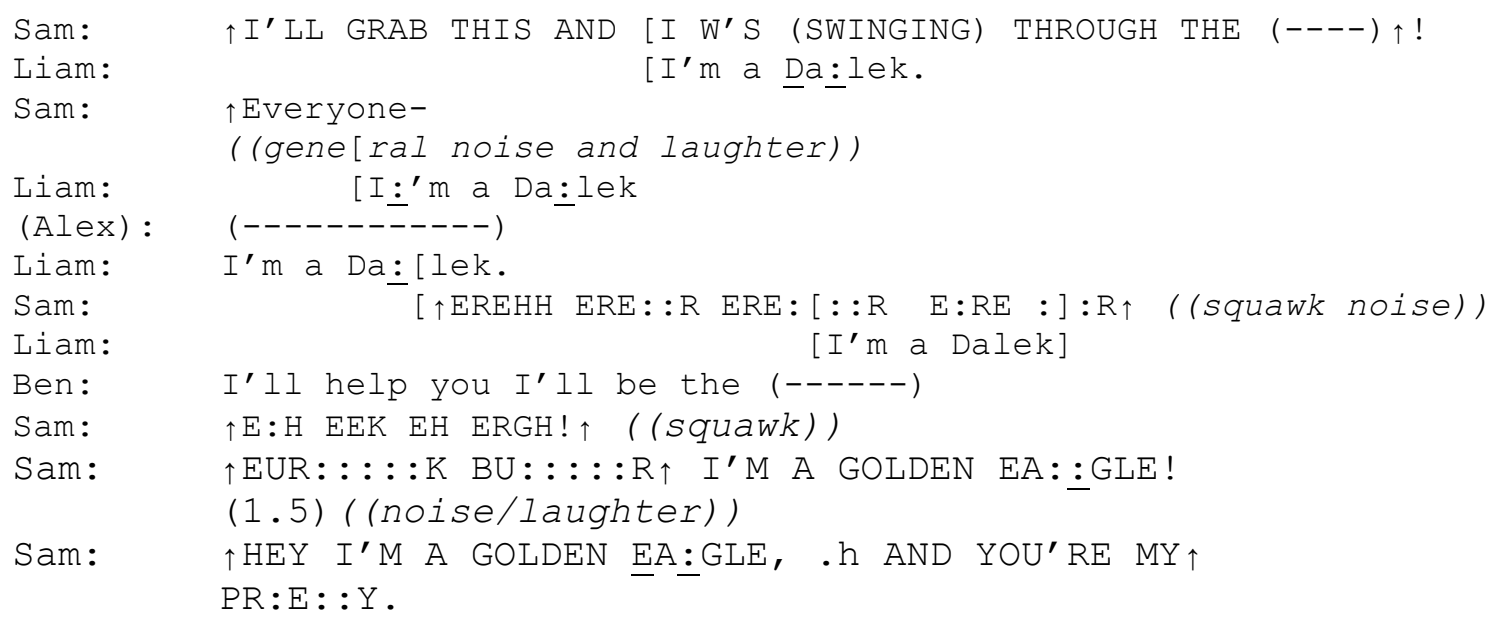

Sam picks up the largest box and makes a loud announcement at line 1 that is not clearly heard by the transcriber. In overlap with this, and much more quietly, Liam - who is walking around with his feet through the bottom of a box - announces he is a 'Dalek' (a type of fictional cyborg from the Doctor Who series). The announcement is a self-mapping through which Liam maps himself as a member of the category of 'Dalek' (Sacks, 1995). As a first move in a potentially new game, it requires some sort of uptake from other players - ideally one in which Liam's membership is ratified by the acknowledgement or acceptance of another child, or by another player mapping themselves into a related play category (e.g. another Dalek, or Doctor Who). 
Liam is unsuccessful. Despite three announcements (lines 2, 5, and 7), he receives no recognition of his role as a Dalek from the other children and there are no subsequent mappings by any of the other children. Part of the trouble is that Liam launches his game in overlap with Sam's much louder announcement (line 2) and in the context of a lot of noise and laughter by the other children (lines 5 and 7). Sam's own mapping as a golden eagle is not a part of the same category-set that would include a Dalek, and it is this competing theme of 'golden eagle' that comes to dominate the collective play for the next several minutes. This play involved Sam holding a broken box behind his back and using the flapping sides as wings, while chasing the other children and making squawking noises.

The effectiveness of Sam's initiation is achieved through several methods. He speaks very loudly which is crucial given the level of noise made by the boys throughout this play episode. His voice is also very animated (similar to 'Bowling! Bowling' in extract 6); an effective attention-getting device. Sam also addresses 'everyone' (line 3) and while he is not heard to complete his turn at this point, this collective address summons the attention of all other players. These are all ways in which Sam is working towards securing the participation of the other children - which is crucial if his proposed activity is to be successful. There is no doubt that Sam secures the attention of the others, with his loud squawking at line 8, but at line 10 he also gets the participation of Ben who briefly stands in front of Sam and holds onto the wings. It is only at line 12 that Sam clearly maps himself as a 'golden eagle', and then at line 14 he maps the other children as his 'prey'. By also mapping the others, he assigns them a role that is paired with a bird of prey and, as such, provides for the relevant play actions of the other players. It is therefore highly effective in getting the participation of the other children in a game of Sam's own design. The eagle subsequently chases his 'prey' for several minutes.

Engagement as a strategy for inviting participation in play is reliant on children's recognition and shared understanding of play moves. It also demonstrates the relevance of a child's affect in starting play. For example, Selena's appropriation of the moon hopper was made playful through the use of a 'play face', and the success of an announcement in initiating play is probably strongly linked to the animation with which it is delivered.

\section{Partitioning: Managing inclusion and exclusion}

We have shown that children's recruitments and engagements play a role in shaping children's participation in play. The use of personal names and collective proterms are important ways of identifying and shaping the participation of other children (also see Bateman, 2012; Butler, 2008). In this final section, we illustrate how inclusion and exclusion is managed with respect to the allocation and use of play resources. One method that children use to manage this is partitioning the members of play - that is, dividing the group of children so that there are different rights accorded to the different sub-groups (Sacks, 1995; also see Butler, 2008 on partitioning in children's play). 
The first example is taken from the beginning of a play session. Kate and Selena have knelt down by a pile of toys and are looking through it, while the two other children (Abbie and Kelly) are standing and watching. Kate picks up a pair of Velcro covered hand mitts and an associated ball and asks Selena what it is:

\section{Extract 9}

[S2G4Toys]

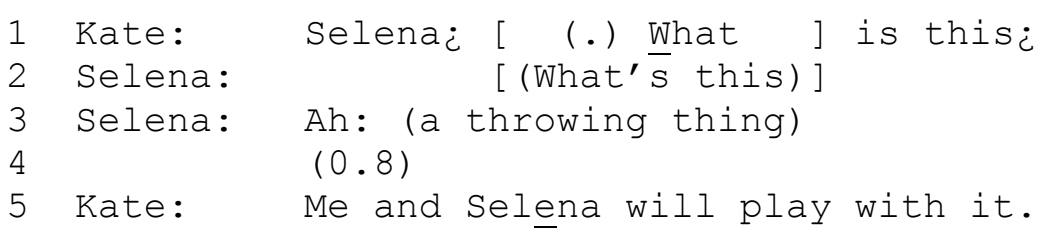

By selecting Selena (by name) to identify the toy, Kate invites Selena's attention and engagement but effectively also excludes the other two children. This is in contrast to Selena's request for identification of another toy (line 2), which would allow any of the children to answer. When Selena identifies the toy as what sounds like 'a throwing thing', Kate follows with an announcement 'me and Selena will play with this'. As an assertion, rather than an invitation, it minimises any opportunity for Selena to say she would want to play with something else, in the way that an alternative formulation (like 'let's play with it' or 'shall we play with it') might do. Importantly, by announcing it in this way, it seems to be designed as news for the other children. Otherwise, saying 'we will play with it' would be more appropriate. So, the announcement serves several functions: it names and establishes the next play activity, it commandeers Selena's involvement, and it excludes Abbie's and Kelly's participation and use of this particular toy. Organizationally, it partitions the group into 'players' and 'non-players' in the new play activity proposed by Kate.

In some cases, children explicitly exclude others from using a toy or play object by claiming possession of it. To illustrate, the following extract is taken from an episode with four boys playing with boxes inside. Adam was lying down inside one large box and was joined by Billy just prior to this extract. Sam picks up another box and moves it away as he makes his announcement in line 1 :

\section{Extract 10}

\section{[S1G1InBox]}

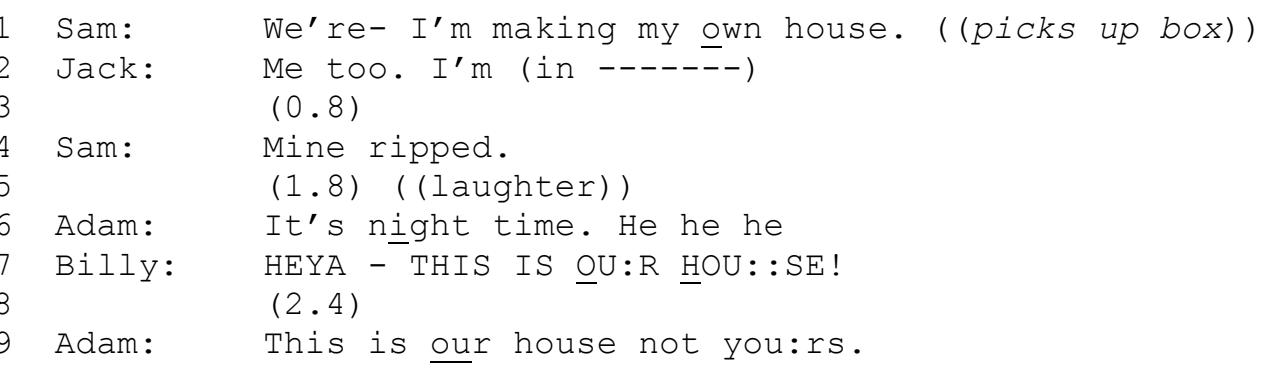


This extract involves a number of announcements that include and exclude each child's participation in the overall play activity by partitioning the group of children in different ways. While Sam (line 1) seems about to begin his announcement with the inclusive 'we,' he repairs this (see Schegloff, 2007) to the singular ' $I$ ' and describes making his 'own house'. By making individual possession relevant here, he excludes Jack's potential participation. At line 7, Billy announces loudly that the box he and Adam are in is 'our house'. This claim of possession, like Sam's, seems designed as an exclusionary tool. Adam then makes exclusion explicit with his subsequent announcement, 'this is our house not yours' (line 9). There was no apparent danger in this fragment of either Sam's or Billy's and Adam's 'houses' being appropriated by Jack so the issue doesn't seem to be about possession of the play objects. Instead, possession and ownership issues are used to partition the children into those with rights to play or not. Participation in play is therefore mediated by the children's allocation of play resources and claims of ownership. As Bateman (2011) found in her analysis of children's use of playground huts, physical objects can serve as boundaries for inclusion and exclusion.

\section{Discussion}

The analysis has identified and discussed various strategies used by children in managing the participation of other children in their play. We identified a range of interactional practices used to manage the type and nature of other children's membership and participation, which can be categorised into three practices for managing participation: recruitments, in which there is an explicit request or invitation or offer of play issued to another child; engagements, in which a play(ful) action serves to mobilise the attention of another child in order to initiate play; and partitioning, by which children divide the group into sub-groups to manage participation and access to play resources. These social practices for managing participation are the means by which children start up play activities and get other children involved. In some cases it can be the difference between a child playing and not playing for instance, if you cannot get someone to play table tennis with you, you cannot play table tennis. In other cases it may be the difference between having some control over the nature of a game and one's role in it - such as whether you get to be a Dalek or 'golden eagle prey'.

The examples above illustrate several of the core issues that shape children's participation in play activities. First, there are a variety of ways of initiating a new game or play episode. Because children can and do use a range of different methods for starting games, it becomes of interest to look at when and how these different methods are used and how they are responded to. Second, different initiating forms have different consequences for how other children can respond - some clearly invite an acceptance or agreement, others seem to assume the involvement (or willing participation) of other children, whereas others invite and rely on a child doing a second play action. Third, the form of the proposal, as well 
as the play activity itself, can have implications for who participates in a game. While the toys and play objects may have different affordances and limitations in terms of participation, these are mediated by the interactional practices that are used to initiate new game activity.

The findings contribute to other interactional studies that have highlighted the collaborative nature of children's play and moment-by-moment organisation of game resources, structure, and membership (e.g. Bateman, 2011, 2012; Butler, 2008; Cobb-Moore et al., 2009; Cromdal, 2011; Danby \& Baker, 1998; Goodwin, 2007; Griswold, 2007; Kyratzis, 2007). A specific contribution has been made to understandings of children's play entry. While most research has focused on how children enter the play of others in games already established (e.g. Cromdal, 2001), this analysis has demonstrated how children recruit others into their play activity, and specifically in initiating a new game activity. The practices identified have implications beyond play with a more general relevance for children's social practices. For example, the analysis aligns with other research on how children initiate action and manage their participation in family interaction (Butler \& Wilkinson, 2013) and furthers understanding about fundamental interactional practices. From a comparative perspective, children seem more able and willing to use a wider range of strategies amongst peers than they do with family members. Further investigation will help unpack the degree to which observed differences are a feature of the type of context (e.g. family dinners versus play in a school library), or the ways in which asymmetries are produced in peer versus family relationships. The use of an interactional analysis enables us to see how contextual features and issues like asymmetry are jointly and locally produced on a turn-by-turn basis (Butler, 2008).

Children's practices for organising social interaction and taking part in physical activity are inextricably linked, due to the social nature of so much of children's play in school settings. While it was clear that toys and boxes facilitate and encourage children's play (Morris et al., 2012) the children's engagement in play, and the physical activity that this requires, was facilitated and shaped by their talk and social interaction. The use of play objects and the play environment is a social product. This examination of some of the social processes that are integral to play activity offers a new way of looking at how play is fostered and organised, with implications for how we understand and research the benefits of play, and children's engagement in various types of play.

The accelerometer data in this study showed that boxes and toys encouraged physical activity (Morris et al., 2012; Sandford et al., forthcoming). As shown in this discussion, the video recordings of the play sessions have also indicated that the children's participation in play was socially produced and organised. Future research aims to explore the interrelationship between these two findings and develop a more rounded understanding of the social processes through which different physical practices are established. The current research opens up a range of questions for future study, and sets out a methodology with 
which such questions can begin to be addressed. For instance, are there any relationships between a child's strategies for recruiting other players and their physical activity? Are children who initiate play activities more active than those who are more likely to be invited into an existing game? On a broader level, future research will examine the interactional practices that drive and shape, as well as limit and stop, active play; and look at whether the category of 'active play' is one that is better understood in terms of measurable physical changes and activity, or in terms of the children's own social practices and understandings. These sorts of questions raise interesting challenges and possibilities in terms of knowledge about play and its benefits, and the methods we use for examining these issues.

Furthermore, greater knowledge about the relationship between social behaviours and children's physical activity in play opens up possibilities for interventions aimed at increasing children's physical activity. Future research aims to explore the potential for teaching children how to engage with peers in play as a means of increasing physical activity. While it is clear that the provision of space, time and objects can support physical activity, much of this activity is social. It follows, then, that supporting children's use of social practices that can help increase their capacity to take part in such play and to encourage the participation of others, will benefit physical activity in play.

\section{Acknowledgements}

The authors gratefully acknowledge the support of the British Toy and Hobby Association who funded the project and have encouraged the dissemination of project findings. In addition, we thank the two anonymous reviewers for their feedback, and would like to recognise the invaluable contribution made by colleagues from the Institute of Youth Sport at Loughborough University, namely: Dr. Mary Nevill, Dr. John Morris, Dr. Trish Gorely, Susie Brown, Gail Matthews, Hayley Musson, Cathie Taylor, Sophie Hobson and James Dorling. Finally, we express our gratitude to the pupils and staff of the two project schools for their participation in the study. 


\section{References}

Bateman, A. (2011). Huts and heartache: The affordance of playground huts for legal debate in early childhood social organisation. Journal of Pragmatics, 43(13), 3111-3121.

Bateman, A. (2012) Forging friendships: The use of collective pro-terms by pre-school children, Discourse Studies, 14, 165-180.

Bateman, A., Danby, S., \& Howard, J. (2013). Living in a broken world: how young children's wellbeing is supported through playing out their earthquake experiences. International Journal of Play, 2(3),

Bateson, G. (1972). Steps to an Ecology of Mind. London: Palladin.

Burton-Jones, N. (1972). Categories of child-child interaction. In N. Blurton-Jones (Ed). Ethological Studies of Child Behaviour. London and Reading: Oxford University Press.

Butler, C.W. (2008). Talk and Social Interaction in the Playground. Aldershot: Ashgate

Butler, C.W. \& Fitzgerald, R. (2010). Membership-in-action: Operative identities in a family meal. Journal of Pragmatics, 42(9), 2462-2474.

Butler, C. \& Weatherall, A. (2006). 'No, we're not playing families': Membership categorisation in children's play', Research on Language and Social Interaction, 39(4), 441-470.

Butler, C.W. \& Wilkinson, R. (2013). Mobilizing recipiency: Child participation and 'rights to speak' in multi-party family interaction. Journal of Pragmatics $X$

Cobb-Moore, Charlotte, Susan Danby, Ann Farrell (2009) 'Young children as rule makers', Journal of Pragmatics 41/8: 1477-1492

Cobb-Moore, C., Danby, S. \& Farrell, A. (2008) "I told you so": justification used in disputes in young children's interactions in an early childhood classroom. Discourse Studies, 10, 595-614.

Corsaro, W. A. (2005). The Sociology of Childhood.( $2^{\text {nd }}$ ed.), California: Pine Forge Press.

Corsaro, W.A. (1979). Children's Use of Access Rituals in a Nursery School. Language in Society, 8 , 315-336.

Cromdal, J. (2001) "Can I be with?" Negotiating play entry in a bilingual school. Journal of Pragmatics, 33, 515-43.

Cromdal, J. (2009) Childhood and social interaction in everyday life: Introduction to the special issue. Journal of Pragmatics, 41(8), 1473-1476.

Cromdal, J. (2011) 'Gender as a practical concern in children's management of play participation'. In: S.A. Speer \& E. Stokoe (Eds.). Conversation and Gender (pp. 294-309). Cambridge: Cambridge University Press. 
Danby, S., \& Baker, C.D. (1998). 'What's the problem? Restoring social order in the preschool classroom'. In I. Hutchby, J. Moran-Ellis (Eds.), Children and Social Competence: Arenas of Action. (pp. 157-186). London: Falmer.

Danby, S. and Baker, C. (2001) Escalating Terror: Communicative Strategies in a Preschool Classroom Dispute. Early Education and Development 12(3), 343-358

Kyratzis, A. (2007). Using the social organizational affordances of pretend play in American preschool girls' interactions. Research on Language and Social Interaction, 40, 321-352.

Feda, D. M., Lambiase, M. J., McCarthy, T. F., Barkley, J. E. \& Roemmich, J. N. (2012), Effect of increasing the choice of active options on children's physically active play, Journal of Science and Medicine in Sport, 15, 334-340.

Goodwin, M. H. (1990). He-Said-She-Said: Talk as Social Organization among Black Children. Bloomington: Indiana University Press.

Goodwin, M.H. (2002). Exclusion in girls' peer groups: Ethnographic analysis of language practices on the playground. Human Development, 45(6), 392-415.

Goodwin, M.H. (2007). Participation and embodied action in preadolescent girls' assessment activity. Research on Language and Social Interaction 40(4). 353-375.

Goodwin, M.H. \& Kyratzis, A. (2007). Children socializing children: Practices for negotiating the social order among peers. Introduction to Research on Language and Social Interaction 40(4). 291-391.

Gray, P. (2011) The decline of play and the rise of psychopathology in Children and Adolescents, American Journal of Play, 3:4, 443-463.

Griswold, O. (2007). Achieving authority: Discursive practices in Russian girls' pretend play. Research on Language \& Social Interaction, 40(4), 291 - 319.

Jefferson, G. (2004). Glossary of transcript symbols with an introduction. In Gene H. Lerner, (Ed.), Conversation Analysis: Studies from the first generation (pp13-31). Amsterdam/Philadelphia: John Benjamins.

Pellegrini, A.D., \& Blatchford, P. (2000). The Child at School: Interactions with Peers and Teachers. London: Arnold.

Pellegrini, A. D., \& Smith, P. K. (1998). Physical activity play: The nature and function of a neglected aspect of play. Child Development, 69(3), 577-598.

Sacks, H. (1995). Lectures on Conversation. Blackwell.

Sattelmair, J. \& Ratey, J. J. (2009) Physically Active Play and Cognition: An academic matter? American Journal of Play, 365-374.

Schegloff, E.A. (2007). Sequence organization in interaction: A primer in conversation analysis. Cambridge: Cambridge University Press. 
Sheldon, A. (1996). You can be the baby brother, but you ain't born yet: Preschool girls' negotiation for power and access in pretend play. Research on Language and Social Interaction, 29, 57-80.

Sidnell, J. (2010). Conversation analysis: An introduction. Wiley-Blackwell.

Theobald, M. (2013). Ideas as "possessitives": Claims and counter claims in a playground dispute. Journal of Pragmatics, 45(1), 1-12.

Valentine, G. \& McKendrick, J. (1997) Children's Outdoor Play: Exploring Parental Concerns About Children's safety and the Changing Nature of Childhood, Geoforum, 28: 2, 219-235).

Whalen, M.R. (1995) Working Toward Play: Complexity in Children's Fantasy Activities. Language in Society, 24, 315-48.

Wood, E. (2007) New Directions in play: consensus or collision, Education 3-13: International Journal of Primary, Elementary and Early Years Education, 35(4), 309-320.

Wootton, A. J. (1997). Interaction and the Development of Mind. Cambridge: Cambridge University Press.

\section{Appendix: Transcription conventions (adapted from Jefferson, 2004)}

(0.2) Timed silence

(.) A micro-pause, less than 0.2 seconds

: $\quad$ Preceding sound is stretched

Word Underlining shows stress or emphasis

WORD Capitalisation shows increased volume

${ }^{\circ}$ word ${ }^{\circ}$ Degree signs show the word is quieter than surrounding talk

$\uparrow \downarrow \quad$ Up and down arrows show marked shifts in pitch

A period represents a falling, final intonation

, Comma shows a slightly rising, continuing intonation

? Shows a rising, questioning intonation

¿ Shows a rising intonation, not quite 'questioning'.

! particularly animated talk

$>$ word $<$ rushed speech 